\title{
Editorial
}

\section{Oxygen in the home}

The importance of oxygen as a therapeutic agent was established by JS Haldane in $1917^{1}$ and by Barcroft in $1920 .^{2}$ The latter divided anoxia into three types: anoxic, anaemic, and stagnant. Breathing of oxygen-enriched air was described as palliative; it enabled tissues to be vitalised while recovery occurred. Both Haldane ${ }^{1}$ and in 1931 Barach $^{3}$ noticed that high inspired oxygen concentrations sometimes caused a rise in the arterial carbon dioxide tension $\left(\mathrm{PaCO}_{2}\right)$. Excessive stimulation of metabolism was erroneously considered to be the cause of the raised $\mathrm{PaCO}_{2}$ and this led to the establishment of intermittent oxygen treatment. Much criticism was levelled at this technique, which only occasionally relieved hypoxic tissue. Comroe and others in $1950^{4}$ described some of the harmful effects of oxygen when used to treat hypoxia in patients with bronchitis and emphysema. Suker and Hickman in $1956^{5}$ related the rise of $\mathrm{PaCO}_{2}$ to respiratory depression caused by high inspired oxygen concentrations in patients with chronic bronchitis, which is the basis of our present understanding. It became clear that high inspired oxygen concentrations could not safely be administered to patients with chronic airways obstruction with any degree of carbon dioxide retention for fear of a further sharp rise in $\mathrm{PaCO}_{2}$, leading to coma through cerebral acidosis. ${ }^{5}$ But patients with hypoxaemia from other causes, such as acute or chronic heart failure, severe anaemia, or even respiratory failure without carbon dioxide retention, could inhale oxygen-enriched air without such problems.

In 1960 Campbell $^{6}$ introduced the concept of controlled oxygen treatment for patients with chronic obstructive lung disease. Inspired oxygen concentrations of no more than $30 \%$ allowed relief of severe tissue hypoxaemia, enabling the arterial oxygen tension $\left(\mathrm{PaO}_{2}\right)$ to rise to $7-8 \mathrm{kPa}(50-60 \mathrm{~mm} \mathrm{Hg})$ without excessive hypercapnia (not more than 9.3-10 kPa (70-75 mm Hg)). In 1966 Campbell and Gebbie $^{7}$ introduced the HAFOE (high airflow with oxygen enrichment) Ventimasks (Vickers Medical). Different masks produced at the nose $24 \%, 28 \%$, $35 \%$, and $40 \%$ nominal inspired oxygen concentrations. Since then a colour code has been introduced, and there are several different manufacturers; a $60 \%$ mask (which is not for the hypercapnic patient) has also been developed. Recently nasal catheters, a simplification of earlier Tudor Edwards nasal spectacles, have been found to be just as effective as HAFOE masks. Pure oxygen at flow rates of 1-2 litres a minute introduced via the nose mixes with inspired air to raise the $\mathrm{PaO}_{2}$ to levels similar to those attained by 24-35\% HAFOE masks. The response of $\mathrm{PaO}_{2}$ to nasal oxygen varies much between patients and the correct flow rate needs to be judged during introduction of treatment by one or two arterial punctures. On present evidence $\mathrm{PaO}_{2}$ values above $8 \mathrm{kPa}(60 \mathrm{~mm} \mathrm{Hg})$ appear to be satisfactory.

Oxygen for hypoxaemia not associated with chronic obstructive lung disease is uncontrolled and rarely measured. It is administered by light face masks such as the MC (Mary Catterall), Hudson, or Polymask.

In the home the use of oxygen has not been fully documented but the results of such studies as have been done are surprising. Throughout the United Kingdom some $300000-400000$ prescriptions are written for oxygen each year. Studies in Southampton $^{8}$ and Sheffield showed that oxygen in the home is taken by the patient for breathlessness with little regard for hypoxaemia. Over $90 \%$ of those who have oxygen equipment administer it to themselves with few instructions other than from the delivering chemists. Oxygen is taken via a face mask at a flow rate of 2 or 4 litres a minute for anything from a few minutes to half an hour. Less than $5 \%$ of patients take oxygen for more than two to three hours a day and only the very occasional patient uses it for more than 12 hours a day. It might be thought that in Britain most oxygen would be consumed in the industrial conurbations of the Midlands, South Yorkshire, and Lancashire. Not so - a study of returns from the Prescription Pricing Bureau has found Oxfordshire and Lincolnshire to be the highest consumers per head of population. ${ }^{9}$ What sort of patients are receiving these oxygen prescriptions is uncertain.

The ad hoc prescribing of domiciliary oxygen is perhaps not surprising as no clear indications for use have ever been defined. Recent work is beginning to sort out the problem. Long-term controlled oxygen treatment has had most attention and there has been more experimental work on the use of portable oxygen. Oxygen treatment for the relief of distres- 
sing dyspnoea without hypoxaemia has been dismissed, probably erroneously, as unphysiological. Non-respiratory indications for home oxygen treatment have never been studied.

\section{Long-term domiciliary oxygen}

After the introduction of controlled oxygen treatment for the hypoxaemic bronchitic patient acute exacerbations (usually heralded by gross peripheral oedema) could be largely controlled in two to three weeks without the need for mechanical ventilation. Patients returned from hospital well but commonly died shortly afterwards when their $\mathrm{PaO}_{2}$ fell again. The overall mortality did not change. ${ }^{10}$ Improvement in pulmonary haemodynamics (fall of pulmonary artery pressure) and a fall in the haematocrit in the intervals between acute exacerbations were found to require oxygen for at least 15 hours a day. ${ }^{11}$ Oxygen for 15 hours a day in the home posed problems of logistics as well as of compliance by patients. Two studies, one in England (by the Medical Research Council) ${ }^{12}$ and one in the United States (the NOTT trial), ${ }^{13}$ were conducted to test efficacy and technique.

In the Medical Research Council trial ${ }^{12}$ patients were selected from three centres on the grounds of arterial hypoxaemia $\left(\mathrm{PaO}_{2}<8 \mathrm{kPa}: 60 \mathrm{~mm} \mathrm{Hg}\right)$ and oedema in association with chronic obstructive lung disease-so-called cor pulmonale. Patients were randomly allocated to domiciliary oxygen and no oxygen groups. Oxygen was given for 15 hours a day at a rate sufficient to raise the $\mathrm{PaO}_{2}$ to at least 8 $\mathrm{kPa}$-around two litres a minute. Other medical treatment continued in all patients. Nasal catheters were used and the oxygen was delivered either by large cylinder, liquid oxygen (Union Carbide Walker System), or oxygen concentrator. This last is an ingenious machine which uses the molecular sieve principle to divide ambient air into a stream of oxygen and nitrogen. Up to $94 \%$ oxygen can be obtained. After five years there were twice as many deaths in the untreated as in the treated group. Women apparently did better than men, in whom, curiously, no improvement was observed for 18 months. In the American NOTT trial ${ }^{13}$ oxygen for 12 hours was compared with 24-hour treatment, although in practice 24-hour treatment was not fully adhered to (the average was 19 hours a day). Nevertheless, at 19 months a significant difference in mortality was observed. Continuous oxygen was associated with half the death rate of the 12-hour schedule. Long-term domiciliary oxygen treatment would seem therefore to have a place in the treatment of cor pulmonale associated with chronic obstructive lung disease (other causes of chronic respiratory hypoxaemia were not studied). But although oxygen caused a fall in haematocrit it could no more than arrest deterioration of pulmonary hypertension.

In both studies, while benefit was clearly obtained, some patients still deteriorated and died despite oxygen. Attempts to improve the selection of patients by the use of physiological indices were fruitless and there is at present no means of selecting those likely to benefit most.

It would be reasonable to recommend long-term domiciliary oxygen in cor pulmonale associated with chronic obstructive lung disease. Selection should be strict and the criteria similar to those used for the MRC trial: $\mathrm{PaO}_{2}<8 \mathrm{kPa}$ in a stable period, some degree of hypercapnia, no other life-threatening disease, and agreement to stop smoking. Breathlessness is not to be confused with hypoxaemia. Treatment is best given by an oxygen concentrator for a minimum of 15 hours a day. Simple thickwalled plastic tubing relayed to the living room and bedroom is quite sufficient to distribute the oxygen and can be installed by a technician in two hours. The cost of the complete system is of the order of £700-1000 per patient per year (depending on whether the machine is purchased or rented), which is much cheaper than any other treatment. With small " $F$ "-sized cylinders (1360 litres), for example, from contracting chemists the cost would be $£ 3000-4000$ a year and with a liquid oxygen system about $£ 1400$ a year.

Oxygen concentrators (Rimmer Birlec, DeVilbiss, Mountain Medical, etc) have been installed in large numbers worldwide but their use has been largely intermittent and uncontrolled. The equipment has not been used long term under prescribed therapeutic conditions. The reliability of the machines under these circumstances still has to be tested. In Britain therefore technical monitoring is essential. All machines can be fitted with time clocks and measurements made of their use by the patient. The benefits of long-term oxygen seem related to compliance with a 15-hour daily regimen. Outside the confines of a research study co-operation might be less, with consequent slippage of therapeutic efficacy, unless close supervision is maintained.

\section{Portable oxygen}

Portable oxygen is usually given to patients with chronic respiratory disease who are hypoxaemic in the hope that the relief of hypoxaemia will increase exercise capacity. Oxygen is given from small, lightweight cylinders fitted with a reducing valve which allows a flow of 2 or 4 litres a minute (Portagen, BOC Ltd, DeVilbiss Ltd). The 230-litre size weighs 
about $2 \frac{1 / 4}{\mathrm{~kg}}$ when loaded and, depending on the flow rate used, will last around half an hour. It has to be refilled from a cylinder in the patient's home through a special device. This is quite difficult and potentially dangerous but there are no reasonable alternatives at present. Liquid oxygen systems weigh $4 \frac{1}{2}-5 \frac{1}{2} \mathrm{~kg}$ when loaded and likewise present a filling risk but they last considerably longer. On the other hand, the extra weight seems to confer an appreciable penalty, ${ }^{14}$ which diminishes the benefit of the oxygen.

Early studies ${ }^{15}$ seemed to show considerable improvement in walking distance as a result of portable oxygen but they were largely uncontrolled. Later studies ${ }^{16}{ }^{17}$ in which oxygen and air were given through cylinder systems in double-blind fashion show very much less advantage once the placebo effect of the system has been discounted. In two recent studies ${ }^{1819}$ the extra distance achieved as a result of the portable oxygen was very small.

Patients have always maintained, however, that breathing oxygen during walking makes exercise much easier. They are less concerned with the distance achieved, although a very small walking capacity becomes a considerable burden when they have to rest after a few metres. Visual-analogue scales ${ }^{19} 20$ used to measure the sensation of breathlessness independently of exercise capacity have shown quite clearly that the sensation of breathlessness is not closely related to exercise capacity. Among patients with short walking distances and poor pulmonary function as indicated by spirometry there are some who deny serious breathlessness, whereas others profess to be impossibly disabled. The sensation of breathlessness and exercise capacity improved independently during oxygen breathing. ${ }^{20}$ Hypoxia has been considered a "dyspnogen" acting irrespective of ventilatory change through mechanisms in which the carotid body is concerned. ${ }^{21}$ Perhaps, then, the patient is right after all: there is benefit from breathing oxygen but it comes in a way that standard exercise tests would not detect. Until further studies have been done portable oxygen should be prescribed cautiously (but not denied) to patients who claim benefit, whether they are hypoxaemic or not.

\section{Short-term oxygen in the home}

Most of the oxygen supplied from 48- $\mathrm{ft}^{3}$ (1360-litre) cylinders delivered from contracting chemists in Britain is taken on a short-term basis. Most patients use it for no more than a few minutes at a time, perhaps only once or twice a week. ${ }^{8}$ Physicians expect the oxygen to be used for relief of hypoxaemia and clearly such intermittent use can be of no value in this respect. The patients maintain that they take it for the relief of breathlessness, particularly during acute exacerbations. when the sensation of breathlessness can become particularly distressing. This use of oxygen has never been closely examined but the recent work on the measurement of breathlessness using visual-analogue scales ${ }^{19} 20$ suggests that oxygen might be of value here. Distressing breathlessness can be relieved with increased inspired oxygen concentrations and this is associated with some reduction of respiratory rate. Relief of breathlessness by oxygen is not limited to patients with low concentrations of arterial oxygen at rest. This work is at an early stage in several laboratories and before the short-term domiciliary use of oxygen is abandoned it would be wise to await reports on this aspect of home use.

Finally, when oxygen is given for non-respiratory conditions such as heart failure or shock, or even respiratory problems where hypercapnia is not a feature, there is no need to limit inspired concentrations to $30 \%$. If in doubt measure the arterial blood. Higher concentrations are often required. There are no immediate constraints, clinical conditions being the determinant. But if oxygen treatment seems likely to be needed for several days the inspired concentration must be limited to the lowest level that will achieve adequate arterial oxygenation. Effective inspired concentrations continuously above $50 \%$ carry the potential hazard of pulmonary oxygen toxicity. ${ }^{22}$

Home oxygen treatment, long the Cinderella of modern therapeutics with haphazard administration, little measurement of response, and no control of therapeutic levels (all the features JS Haldane warned against in $1917^{1}$ ) has now been shown to have several therapeutic effects deserving fuller evaluation. The beneficial effect of oxygen in those with low levels of arterial oxygen tension secondary to respiratory disease is clearly important but its potential for the suppression of distressing dyspnoea in non-hypoxaemic patients comes as a surprise.

\section{P HOWARD Department of Medicine Royal Hallamshire Hospital Sheffield}

\section{References}

' Haldane JS. The therapeutic administration of oxygen. Br Med J 1917;i:181-3.

${ }^{2}$ Barcroft J. Oxygen therapy. Br Med J 1920;i:150-2.

${ }^{3}$ Barach AL. Therapeutic use of oxygen in heart disease. Ann Intern Med 1931;5:428-40. 
4 Comroe JH, Bahnson ER, Coates EO. Mental changes occurring in chronically anoxemic patients during oxygen therapy. JAMA 1950;143:1044-8.

${ }^{5}$ Suker HO, Hickman JB. Carbondioxide intoxication. The clinical syndrome, its etiology and management with particular reference to the use of mechanical respiration. Medicine (Baltimore) 1956;35:389-423.

6 Campbell EJM. Respiratory failure. The relation between oxygen concentration of inspired air and arterial blood. Lancet 1960;ii:10-1.

${ }^{7}$ Campbell EJM, Gebbie T. Masks and tent for providing controlled oxygen concentrations Lancet 1966;i:468-9.

${ }^{8}$ Jones MM, Harvey JE, Tattersfield AE. How patients use domiciliary oxygen. $\mathrm{Br}$ Med $J ; \mathrm{i}: 1397-400$.

9 Williams BT. Geographical variations in the supply of domiciliary oxygen $\mathrm{Br} \mathrm{Med} J$ 1981;282:1941-3.

${ }^{10}$ Ude AC, Howard P. Controlled oxygen therapy and pulmonary heart failure. Thorax 1971;26:572-8.

"Stark RD, Finnegan P, Bishop JM. Long term domiciliary oxygen therapy in chronic bronchitis with pulmonary hypertension. $\mathrm{Br}$ Med J 1973;iii:367-70.

${ }^{12}$ Medical Research Council Domiciliary Oxygen Trial. Lancet 1981;i:681-5.

${ }^{13}$ Nocturnal Oxygen Therapy Trial Group (NOTT Trial). Continuous or nocturnal oxygen therapy in hypoxemic chronic obstructive lung disease. Ann Intern Med 1980;93:394-9.
${ }^{14}$ Leggett RJE, and Flenley DC. Portable oxygen and exercise tolerance in patients with chronic hypoxic cor pulmonale. Br Med J 1977;ii:84-6.

${ }^{15}$ Cotes JE, Gilson JC. Effect of oxygen on exercise ability in chronic respiratory insufficiency. Lancet 1956;i:872-6.

${ }^{16}$ Lilker EJ, Karnick A, Lerner L. Portable oxygen in chronic obstructive lung disease with hypoxemia and cor pulmonale. Chest 1975;68:236-41.

${ }^{17}$ Bradley BL, Garner AE, Billium D. Oxygen assisted exercise in chronic obstructive lung disease. Am Rev Respir Dis 1978;118:239-43.

18 Woodcock AA, Gross ER, Geddes DM. Oxygen relieves breathlessness in "pink puffers." Lancet 1981;i:907-9.

19 Waterhouse JC, Howard P. Breathlessness and portable oxygen in chronic obstructive airways disease. Thorax (in press).

${ }^{20}$ Mitchell-Heggs P, Murphy K, Minty K, et al. Diazepam in the treatment of dyspnea in the "pink puffer" syndrome. $Q J$ Med 1980;49:9-20.

${ }^{21}$ Adams L, Chronos N, Guz A. The dyspnogenic effect of hypoxia-dissociation from ventilatory response. Clin Sci 1982;63:17P.

${ }^{22}$ Nash G, Blennerhassett JB, Pontoppidan H. Pulmonary lesions associated with oxygen therapy and artificial ventilation. $N$ Eng $J$ Med 1967;276:368-74. 